Article

\title{
Low Molecular Weight, 4-O-Sulfation, and Sulfation at Meta-Fucose Positively Promote the Activities of Sea Cucumber Fucoidans on Improving Insulin Resistance in HFD-Fed Mice
}

\author{
Shiwei Hu ${ }^{1}$, Sichun Chen ${ }^{1}$, Hongli Zhu ${ }^{1}$, Mengyu Du ${ }^{1}$, Wei Jiang ${ }^{1}$, Yu Liu ${ }^{1}$, Xiang Gao ${ }^{2,3, *}$, Laijin Su ${ }^{4, *}$ \\ and Yangli $\mathrm{Xu}^{5}$
}

check for

updates

Citation: Hu, S.; Chen, S.; Zhu, H.; Du, M.; Jiang, W.; Liu, Y.; Gao, X.; Su, L.; Xu, Y. Low Molecular Weight, 4-O-Sulfation, and Sulfation at Meta-Fucose Positively Promote the Activities of Sea Cucumber Fucoidans on Improving Insulin Resistance in HFD-Fed Mice. Mar. Drugs 2022, 20, 37. https://doi.org/ $10.3390 / \mathrm{md} 20010037$

Academic Editor: Hitoshi Sashiwa

Received: 10 December 2021

Accepted: 27 December 2021

Published: 29 December 2021

Publisher's Note: MDPI stays neutral with regard to jurisdictional claims in published maps and institutional affiliations.

Copyright: (c) 2021 by the authors. Licensee MDPI, Basel, Switzerland. This article is an open access article distributed under the terms and conditions of the Creative Commons Attribution (CC BY) license (https:/ / creativecommons.org/licenses/by/ $4.0 /)$.
1 National Engineering Research Center for Maine Aquaculture, Zhejiang Ocean University, Zhoushan 316022, China; hushiweihai@163.com (S.H.); cscpurity@163.com (S.C.); zhuhongli2020@163.com (H.Z.); dumengyu816@163.com (M.D.); jiangwei_zjou@163.com (W.J.); liuyu1987@zjou.edu.cn (Y.L.)

2 College of Life Sciences, Qingdao University, Qingdao 266071, China

3 Anqiu Huatao Food Co., Ltd., Weifang 262100, China

4 College of Life and Environmental Science, Wenzhou University, Wenzhou 325035, China

5 Wenzhou Characteristic Food Resources Engineering and Technology Research Center, Wenzhou Academy of Agricultural Science, Wenzhou 325006,China; xuyangli@163.com

* Correspondence: gaoxiang@qdu.edu.cn (X.G.); sulaijin@126.com (L.S.); Tel.: +86-0580-8129858 (X.G.)

\begin{abstract}
Fucoidans from sea cucumber (SC-FUC) have been proven to alleviate insulin resistance in several species. However, there are few studies that clarify the relationship between their structure and bioactivity. The present study evaluated the influence of molecular weight (Mw), sulfation concentrations (Cs), and sulfation position on improving insulin resistance using SC-FUC. Results showed that fucoidans with lower Mw exerted stronger effects. Having a similar Mw, Acaudina molpadioides fucoidans (Am-FUC) with lower Cs and Holothuria tubulosa fucoidans with higher Cs showed similar activities. However, Isostichopus badionotus fucoidans (higher Cs) activity was superior to that of low-Mw Thelenota ananas fucoidans (Ta-LFUC, lower Cs). Eliminating the effects of Mw and Cs, the bioactivity of $A m$-FUC with sulfation at meta-fucose exceeded that of Ta-FUC with sulfation at ortho-position. Moreover, the effects of Pearsonothuria graeffei fucoidans with 4-O-sulfation were superior to those of $\mathrm{Am}$-LFUC with 2-O-sulfation. These data indicate that low $\mathrm{Mw}, 4-\mathrm{O}$-sulfation, and sulfation at meta-fucose contributed considerably to insulin resistance alleviation by SC-FUC, which could accelerate the development of SC-FUC as a potential food supplement to alleviate insulin resistance.
\end{abstract}

Keywords: sea cucumber; fucoidans; low molecular weight; 4-O-sulfation; sulfation at ortho-fucose; insulin resistance

\section{Introduction}

The occurrence and development of insulin resistance is a complex pathological process caused by a decline in insulin sensibility of insulin target organs, subsequent blocking of insulin signaling transduction, and an ultimate decrease in intracellular glucose uptake and utilization [1]. In insulin resistance, insulin is unable to effectively combine with insulin receptors, and subsequently, the phosphoinositide 3-kinase/protein kinase B signaling is blocked [2]. This eventually leads to significant decreases both in both glucose transporter 4 (Glut4) translocation from the cytoplasm to the cytomembrane and glycogen synthase phosphorylation (p-GS) [3,4]. On the other hand, there is a decline in the activities of hexokinase (HK) and pyruvate kinase (PK), which are crucial for glucose utilization in cells to produce energy or glycogen synthesis [5]. Moreover, the activities of glycogen phosphorylase (GP) and glucose-6-phosphatase (G6Pase) are elevated, which catalyze gluconeogenesis reactions to release glucose in the blood [6]. Increasing attention has 
been paid to insulin resistance because of its adverse effects. It has been confirmed that insulin resistance underlies the morbidity of several metabolic disorders, including obesity, inflammation, type 2 diabetes mellitus, and certain cancers [7-9]. There were more than 650 million obese people in the world in 2019, of which over 80\% showed significant insulin resistance and over 420 million suffered from diabetes [10]. According to the International Diabetes Federation, approximately $90 \%$ of type 2 diabetic patients exhibit apparent insulin resistance, and the number of the patients is likely to exceed 600 million by 2035 [11]. Thus, prevention and control of insulin resistance have been an important goal in human health

Fucoidans from sea cucumber (SC-FUC) are polysaccharides comprised of an L-fucose backbone and a sulfate group backbone [12]. SC-FUC are widely considered to possess great potential as a functional food ingredient profiting due to their various bioactivities, including anti-oxidant, anti-tumor, anti-hyperglycemia, hematopoiesis, and anti-hyperlipidemia activities, among others [13-15].

It has been widely acknowledged that the structural features of polysaccharides determine their biological activities. Chain conformation, molecular weight $\left(\mathrm{M}_{\mathrm{W}}\right)$, and sulfation are considered important factors that significantly influence fucoidans derived from marine invertebrates [16]. Linear structures with uniform repeating units are the universal in SC-FUC, which has been identified as ideal for investigating their structurefunction relationship [17]. SC-FUC have uniform repeating tetrasaccharide units with an $\alpha-1,3$-glycosidic linkage, with their differences lying in their molecular weight, sulfation concentrations $\left(\mathrm{C}_{\mathrm{S}}\right)$, sulfation pattern (2-O-, 4-O-, or 2,4-O-sulfo group substitution), and sulfation location (sulfo group at ortho-fucose or meta-fucose) depending on the species. Several SC-FUC have been demonstrated to improve insulin resistance, including fucoidans from Acaudina molpadioides (Am-FUC) [18], Isostichopus badionotus (Ib-FUC) [19], Cucumaria frondosa [20], Holothuria leucospilota [21], and fucoidans from Pearsonothuria graeffei (PgFUC) [22]. However, the effect of the structure-function relationship of SC-FUC on insulin resistance is yet to be determined.

In the present study, we aimed to investigate the effect of the structure-function relationship of SC-FUC on alleviating insulin resistance in high-fat diet (HFD)-induced insulin-resistant mice. For $\mathrm{M}_{\mathrm{w}}, A m$-FUC with different $\mathrm{M}_{\mathrm{w}}$ by an intracellular enzyme (Wenyingzhuangia fucanilytica CZ1127) were used to explore insulin resistance mitigation effects [23]. To determine the influence of $\mathrm{C}_{\mathrm{s}}, \mathrm{Am}$-FUC and $\mathrm{Ht}$-FUC, depolymerized Ta-FUC and $I b$-FUC were used to comparatively analyze the activities of SC-FUC with similar $\mathrm{M}_{\mathrm{w}}$ but different $\mathrm{C}_{\mathrm{s}}$. Am-FUC (sulfo group at meta-fucose) and Ta-FUC (sulfo group at ortho-fucose) with similar $\mathrm{M}_{\mathrm{w}}$ and $\mathrm{C}_{\mathrm{s}}$ were comparatively examined for the influence of structure-function sulfation location. To determine the influence of structure-function sulfation pattern, depolymerized $\mathrm{Am}$-LUC (with a 2-O-sulfation) and $\mathrm{Pg}$-FUC (with a 4-O-sulfation) were comparatively analyzed (Figure 1). 


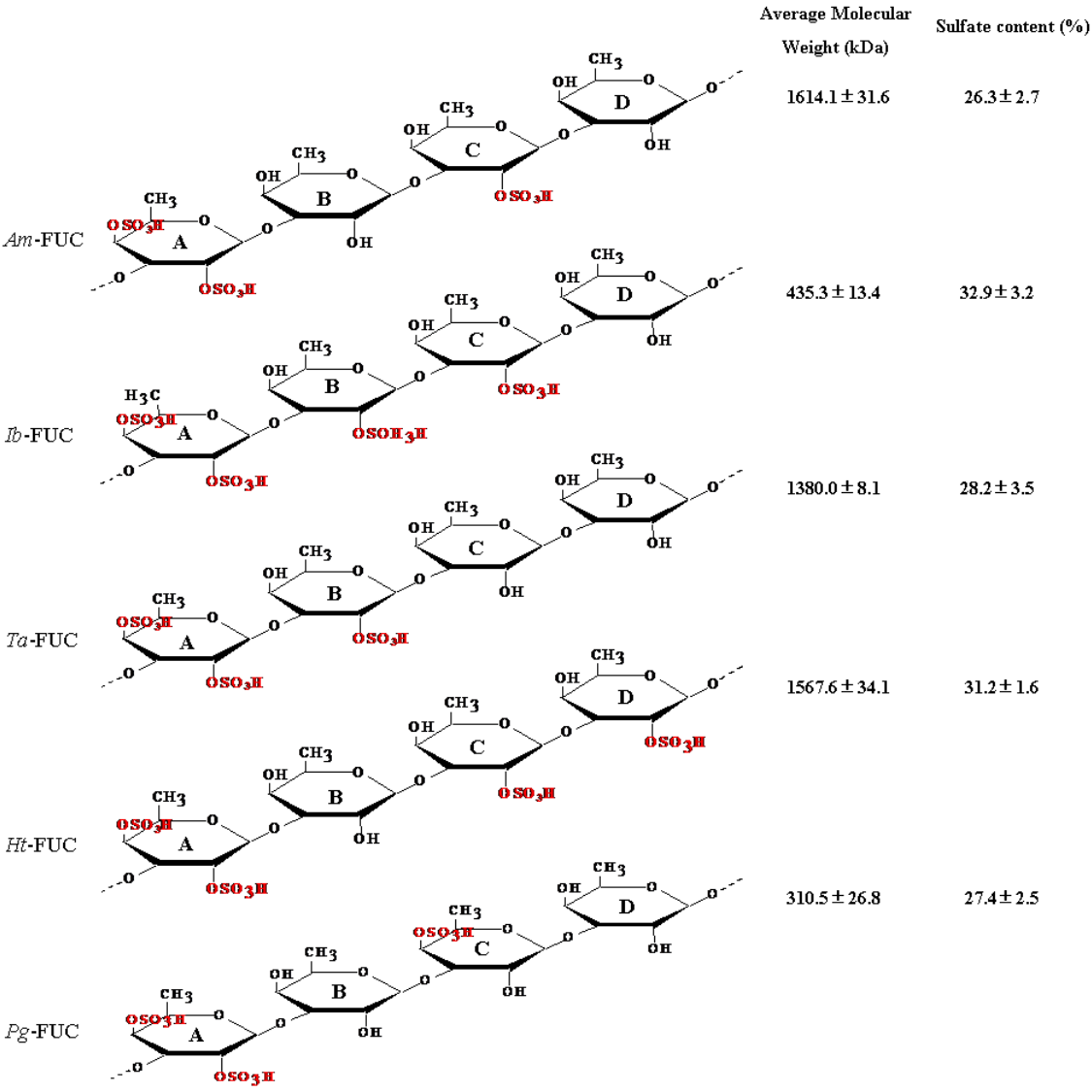

Figure 1. The structure, molecular weight, and sulfation concentration of fucoidans from 5 sea cucumbers. 2,4DS-fucose was defined as fucose A, following with fucoses B, C, and D. Sulfation at fucose $B$ and $D$ (neighboring fucose $A$ ) was named sulfation at ortho-fucose position, while sulfation at fucose C (spacing fucose A) was named sulfation at meta-fucose position $[19,20]$. Acaudina molpadioides fucoidans, Am-FUC; Isostichopus badionotus fucoidans, Ib-LFUC; Thelenota ananas fucoidans, Ta-LFUC; Holothuria tubulosa fucoidans, Ht-LFUC; Pearsonothuria graeffei fucoidans, Pg-LFUC.

\section{Results}

\subsection{Effects of Fucoidans with Different $M_{w}$ on Insulin Resistance}

We evaluated the insulin resistance-alleviation activities of fucoidans with different $\mathrm{M}_{\mathrm{w}}$ using $A m$-FUC and the four depolymerized Am-LFUCs. As shown in Figure 2A, $A m$-FUC and the four $A m$-LFUCs all caused significant decreases in body weight gain $(p<0.05)$, and the effect of Am-LFUC4 was better than that of Am-FUC $(p<0.05)$. Notably, the smaller the fucoidans $\mathrm{M}_{\mathrm{W}}$, the lower the body weight gain observed in experimental mice compared with the HFD group.

Blood glucose and insulin levels, including HOMIA-IR and QUICKI values, blood glucose changes in OGTT and IITT experiments, are usually the common parameters to indicate insulin resistance. There was no significant difference in fasting blood glucose between the HFD and Am-FUC groups. However, fasting blood glucose levels were remarkably reduced by $15.13,17.38,21.02$, and $27.31 \%$ in the four Am-LFUCs groups compared with the HFD group $(p<0.05$ Figure $2 \mathrm{~B}$ ). For serum insulin concentration, the $A m$-FUC and the four Am-LFUC groups significantly lowered the serum insulin level by 14.57, 18.07, 21.15, 24.83, and 30.89\% ( $p<0.05$ Figure 2C) compared with the HFD mice, respectively. HOMIA-IR values were significantly decreased in Am-FUC and the four Am-LFUC groups ( $p<0.05$ Figure 2D) compared with the HFD mice, and the activity of $A m$-LFUC4 was superior to that of Am-FUC $(p<0.05)$. QUICKI scores were remarkably increased in the four Am-LFUC groups $(p<0.05)$, and Am-LFUC4 was more effective than Am-FUC. Nevertheless, there was no significant difference between Am-FUC-treated 
and HFD-fed mice (Figure 2E). In the OGTT and IITT experiments (Figure 2F-I), AmFUC markedly decreased the AUCs by 12.89 and $19.93 \%(p<0.05)$, respectively. When administrated with $A m$-LFUCs, $A_{\text {UUC }}$ OGTT and $\mathrm{AUC}_{\text {IITT }}$ were significantly and sequentially decreased in the Am-LFUC1 group (19.13 and 24.50\%, respectively, $p<0.05)$, Am-LFUC2 group (23.57 and $25.80 \%$, respectively, $p<0.05)$, Am-LFUC3 group (29.24 and $31.88 \%$, respectively, $p<0.05$ ), and Am-LFUC4 group (38.67 and 39.40\%, respectively, $p<0.05$ ). Interestingly, $\mathrm{AUC}_{\mathrm{OGTT}}$ in the Am-LFUC4 group was markedly lower than that of the Am-FUC group compared with HFD-fed mice $(p<0.05)$.
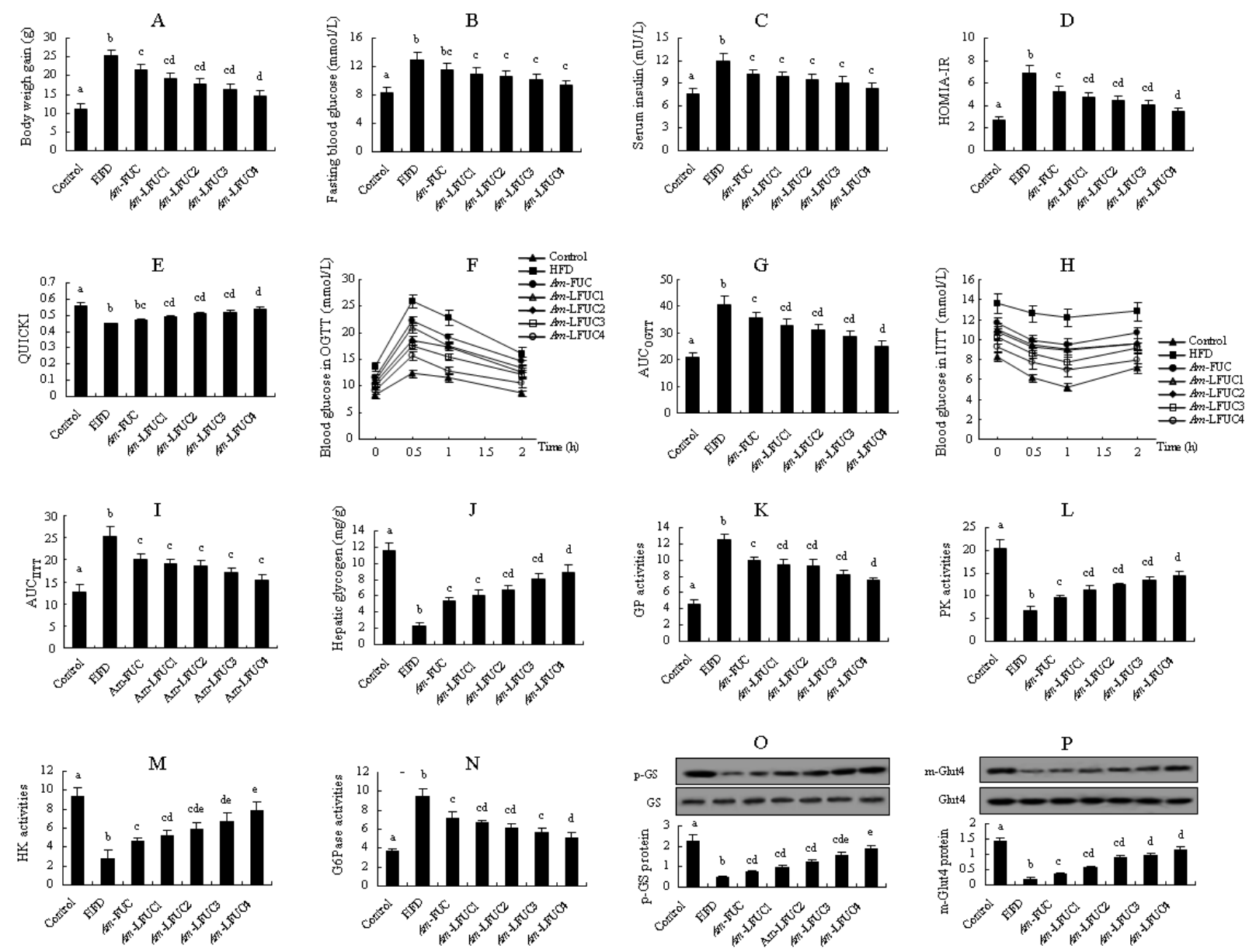

Figure 2. Effects of $A m$-FUC with different molecular weights on alleviating insulin resistance in HFD-fed mice. Acaudina molpadioides fucoidans, Am-FUC. Am-FUC and the 4 depolymerized AmLFUCs had the similar sulfate contents and different Mw. (A), Body weight gain; (B), Fasting blood glucose; (C), Serum insulin; (D), homeostasis model assessment of insulin resistance index (HOMAIR) value; (E), quantitative insulin sensitivity check index (QUICKI) score; (F), oral glucose tolerance test (OGTT); (G), areas under the curve (AUC) in OGTT test; $(\mathbf{H})$, intraperitoneal insulin tolerance test (IITT); (I), AUC in IITT test; (J), Hepatic glycogen; (K), GP activities; (L), PK activities; (M), HK activities; (N), G6Pase activities; (O), p-GS protein expression (p-GS and GS, 85 kDa); (P), m-Glut4 protein expression ( $\mathrm{m}-\mathrm{Glut} 4$ and Glut4, $43 \mathrm{kDa}$ ). Body weight gain was assessed using $12 \mathrm{mice}$. OGTT and IITT were assessed using 6 mice, respectively. p-GS protein was assessed using the 3 mice with $40 \mathrm{U} / \mathrm{kg}$ insulin stimulation while $\mathrm{m}$-Glut4 protein was assessed with $0.5 \mathrm{U} / \mathrm{kg}$ insulin. The other parameters were assessed using the 6 mice treated with normal saline. Different lowercase letters represent significant difference $(p<0.05)$ compared between groups.

Insulin resistance preferentially occurred in the liver, and glycogen content and the related enzymes activities could give a visually direction. In the liver of insulin-resistant mice, glycogen content, and PK and HK activity were significantly enhanced by 1.29-fold, 
41.57\%, and 64.89\% ( $p<0.05)$, respectively, in the Am-FUC group, whereas GP and G6Pase activities were obviously lowered 20.47 and $24.55 \%(p<0.05)$, respectively (Figure $2 \mathrm{~J}-\mathrm{N})$. When treated with Am-LFUCs, the mice in the four Am-LFUC groups showed significant increases in hepatic glycogen contents by 1.59-, 1.86-, 2.43-, and 2.80-fold ( $p<0.05)$, PK activities by $68.34,84.32,100.00 \%$, and 1.14 -fold $(p<0.05)$, HK activities by $84.04 \%, 1.11-$, 1.37-, and 1.78-fold ( $p<0.05)$. Moreover, GP and G6Pase activities were dramatically decreased (GP, 24.24, 24.96, 33.87, and 39.73\%; G6Pase, 29.52, 35.24, 40.53, and 46.88\%, respectively) in the four Am-LFUC groups compared with the HFD group. The effects of $A m$-LFUC4 on GP, PK, and G6Pase activities were superior to those of $A m$-FUC $(p<0.05)$. $A m$-LFUC4 resulted in higher HK activities than both $A m$-FUC and Am-LFUC1 $(p<0.05)$.

We also determined p-GS protein in the liver tissue and $\mathrm{m}-\mathrm{Glut} 4$ protein in the skeletal muscle tissue using Western blotting. As shown in Figure 2O,P, Am-FUC and the four Am-LFUCs significantly increased p-GS protein expressions by 59.57\%, 1.09-, 1.64-, 2.36-, and 2.96-fold $(p<0.05)$, respectively. Additionally, m-Glut4 protein expressions were also significantly increased by 0.94-, 2.11-, 3.89-, 4.39-, and 5.33-fold ( $p<0.05)$ in Am-FUC- and its four depolymerized polysaccharide-treated mice. Interestingly, the effect of $A m$-LFUC4 on the p-GS protein was better than that of Am-FUC, Am-LFUC1, and Am-LFUC2 $(p<0.05)$, and Am-LFUC4 also exhibited higher efficacy on m-Glut4 protein than Am-FUC $(p<0.05)$.

The aforementioned results showed that Am-FUC and the four Am-LFUCs could improve insulin resistance, and the effects of $A m$-LFUCs were better than those of $A m$ FUC. Interestingly, $A m$-LFUC, with its smaller $\mathrm{M}_{\mathrm{w}}$, exhibited stronger insulin resistancealleviation activity, demonstrating that low $\mathrm{M}_{\mathrm{w}}$ fucoidans are more effectively at mitigating insulin resistance than large $\mathrm{M}_{\mathrm{w}}$ polysaccharides.

\subsection{Effects of Fucoidans with Different $C_{S}$ on Insulin Resistance}

Sulfation is closely related to the bioactivity of fucoidans. The $\mathrm{M}_{\mathrm{w}}$ and $\mathrm{C}_{\mathrm{s}}$ of $A m-\mathrm{FUC}$ were $1614.1 \pm 31.6 \mathrm{kDa}$ and $26.3 \pm 2.7 \%$, while those of $H t$-FUC were $1567.6 \pm 34.1 \mathrm{kDa}$ and $31.2 \pm 1.6 \%$, respectively, suggesting $A m$-FUC and $H t$-FUC had similar $\mathrm{M}_{\mathrm{w}}$, whereas the $\mathrm{C}_{\mathrm{s}}$ of $\mathrm{Ht}$-FUC was significantly higher due to one more sulfation in saccharide unit $\mathrm{A}$ (Figure 1). Therefore, we compared the insulin resistance-alleviating activities of $A m$-FUC and $\mathrm{Ht}$-FUC, to determine the effect of $\mathrm{C}_{\mathrm{s}}$ in fucoidans on insulin resistance.

As shown in Figure 3, body weight gain was significantly decreased in the Am-FUC and $H t$-FUC group by 14.74 and $17.03 \%(p<0.05)$, respectively, compared with HFD-fed mice. Am-FUC and Ht-FUC both caused considerable reductions in serum insulin and HOMIA-IR score compared with the HFD group (serum insulin, 14.57 vs. 14.32\%; HOMIAIR, 23.80 vs. $24.53 \%$, respectively, $p<0.05$ ), while neither of them significantly affected fasting blood glucose and QUICKI value. OGTT and IITT data indicated that Am-FUC and Ht-FUC had the quite blood glucose levels and similar AUC (OGTT, 14.46 vs. 13.76\%; IITT, 19.93 vs. $20.81 \%$, respectively, $p<0.05$ ). Moreover, hepatic glycogen contents, and PK and $\mathrm{HK}$ activities were all significantly elevated in the two fucoidan-treated mice compared with the insulin-resistant animals (hepatic glycogen, 1.29 fold vs. 1.22 fold; PK, 41.57 vs. 39.31\%; HK, 64.89 vs. $62.99 \%$, respectively), while GP and G6Pase activities were both remarkably lowered (GP, 20.47 vs. 19.18\%; G6Pase, 24.55\% vs. 23.12\%, respectively). Furthermore, the mice administrated with $A m$-FUC and Ht-FUC showed significant increases in p-GS protein expression in the liver by 1.71 fold and 1.65 fold, and m-Glut 4 protein expression in the skeletal muscle by 69.57 and $73.91 \%$, respectively. These results implied that $A m$ FUC and $H t$-FUC exerted similar insulin resistance-alleviating activity, indicating that $\mathrm{C}_{\mathrm{s}}$ had little impact on fucoidan-improved insulin resistance. However, these results were not persuasive because sulfation is indeed a pivotal functional group in fucoidans. Thus, further investigation is needed. 

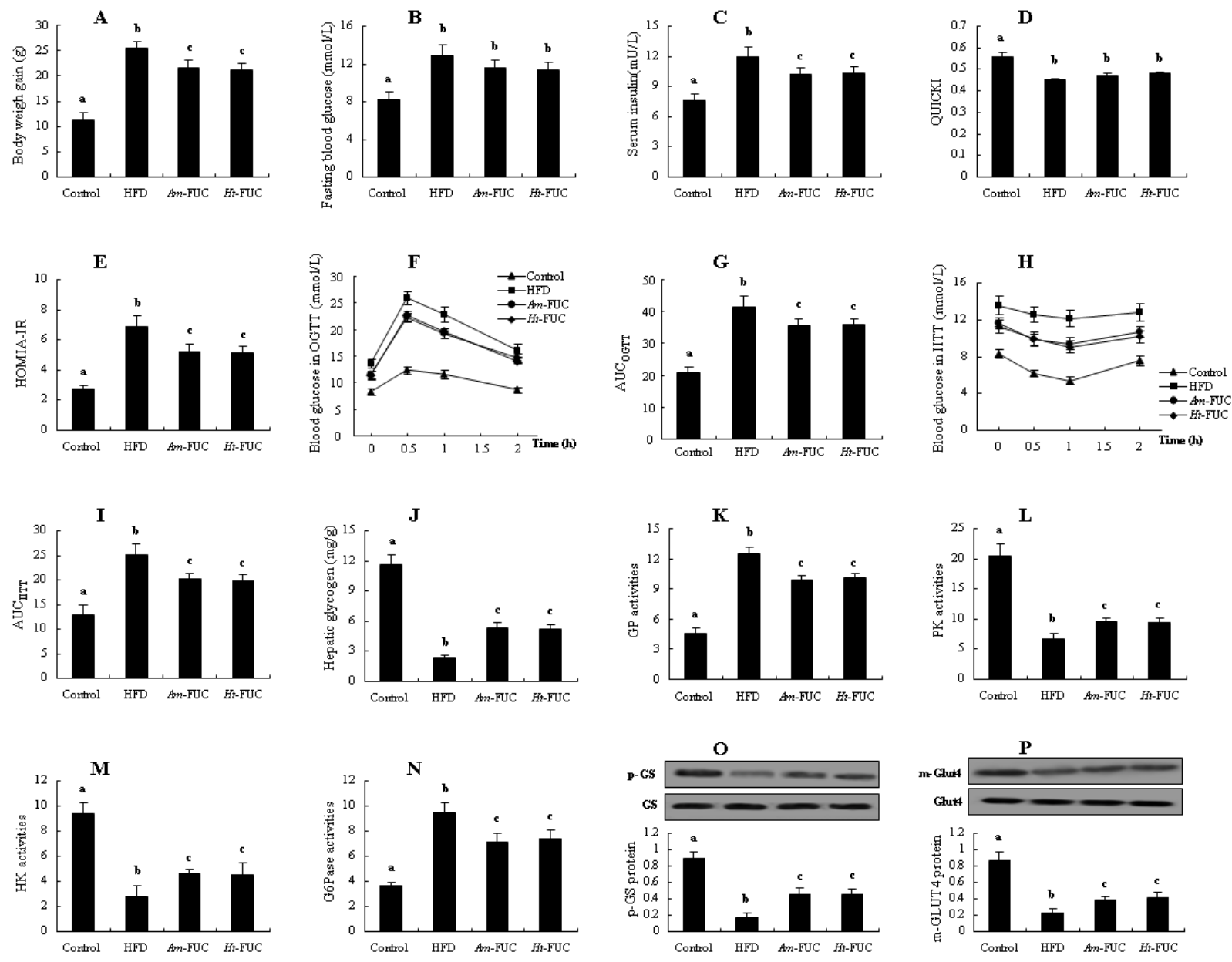

Figure 3. Comparatively analyzing the effects of between Am-FUC and Ht-FUC (similar molecular weight but different sulfation concentration) on alleviating insulin resistance in HFD-fed mice. Acaudina molpadioides fucoidans, Am-FUC; Holothuria tubulosa fucoidans, Ht-LFUC. (A), Body weight gain; (B), Fasting blood glucose; (C), Serum insulin; (D), HOMIA-IR value; (E), QUICKI score; (F), OGTT test; (G), AUC in OGTT test; (H), IITT test; (I), AUC in IITT test; (J), Hepatic glycogen; (K), GP activities; (L), PK activities; (M), HK activities; (N), G6Pase activities; (O), p-GS protein expression (p-GS and GS, $85 \mathrm{kDa}$ ); (P), m-Glut4 protein expression (m-Glut4 and Glut4, $43 \mathrm{kDa}$ ). Body weight gain was assessed using 12 mice. OGTT and IITT were assessed using 6 mice, respectively. p-GS protein was assessed using the 3 mice with $40 \mathrm{U} / \mathrm{kg}$ insulin stimulation while m-Glut4 protein as $0.5 \mathrm{U} / \mathrm{kg}$ insulin. The other parameters were assessed using the 6 mice treated with normal saline. Different lowercase letters represent significant difference $(p<0.05)$ compared between groups.

In the following experiments, we comparatively investigated the effects of Ta-LFUC and $I b$-FUC in alleviating insulin resistance. The two fucoidans had similar $\mathrm{M}_{\mathrm{W}}(450.7 \pm 15.1$ vs. $435.3 \pm 13.4 \mathrm{kDa})$ and distinguished $\mathrm{C}_{\mathrm{s}}(28.4 \pm 3.9$ vs. $32.9 \pm 3.2 \%)$. Results are presented in Table 1 and Figure 4. Both fucoidans significantly reduced body weight gain by 9.40 and $37.32 \%(p<0.05$, Table 1$)$, respectively. However, only $I b$-FUC remarkably decreased body weight gain, fasting blood glucose, serum insulin, HOMIA-IR score, and increased QUICKI value relative to HFD mice $(p<0.05)$. There was no significant difference in these five insulin resistance-related parameters between the Ta-LFUC and HFD groups $(p>0.05)$. In OGTT, Ta-LFUC-treated mice showed marked reductions in blood glucose at 1 and $2 \mathrm{~h}$ compared with HFD-fed mice, while the mice in the $I b$-FUC group exhibited noticeable decreases throughout the OGTT process. The reductions in AUC OGTT attributed to Ta-LFUC and $I b$-FUC relative to the HFD group were 10.69 and $36.66 \%$, respectively. In IITT, $\mathrm{Ib}$-FUC resulted in conspicuous improvements in blood glucose and $\mathrm{AUC}_{\text {IITT }}(p<0.05)$, 
while Ta-LFUC had no significant effect. Moreover, as shown in Table 1, in the liver tissues, glycogen content and glycometabolism-related enzymatic activities were no significantly altered. In contrast, the mice in the Ib-FUC group experienced dramatic increases in hepatic glycogen content, and PK and HK activities by 2.75-, 1.25-, and 1.67-fold $(p<0.05)$ compared with HFD-fed mice, as well as considerable decreases in GP and G6Pase activities by 35.15 and $45.61 \%(p<0.05)$, respectively. Additionally, Figure 4A,B show that $I b$-FUC could dramatically enhance $\mathrm{p}$-GS protein expression in the liver and $\mathrm{m}$-Glut4 protein expression in the skeletal muscle in insulin-resistant mice $(p<0.05)$. In contrast, p-GS and m-Glut4 protein expression were not significantly altered in the Ta-LFUC group compared with the HFD group. Evidence shows that the effects of $I b$-FUC with higher $C_{\mathrm{s}}$ were superior to those of $T a$-LFUC with lower $C_{s}$, suggesting that sulfation is vital for fucoidans in mitigating insulin resistance.

Table 1. Comparison analysis on several insulin resistance-related parameters between $\mathrm{Ta}$-LFUC and Ib-FUC, Ta-FUC and Am-FUC in HFD mice.

\begin{tabular}{|c|c|c|c|c|c|c|c|}
\hline & & Control & HFD & Ta-LFUC & Ib-FUC & Ta-FUC & Am-FUC \\
\hline \multicolumn{2}{|c|}{ Body weight gain $(\mathrm{g})$} & $11.16 \pm 1.47^{\mathrm{a}}$ & $25.43 \pm 1.25^{b}$ & $23.04 \pm 1.33^{b}$ & $15.94 \pm 1.41^{\mathrm{d}}$ & $24.37 \pm 1.72^{b}$ & $21.68 \pm 1.39^{c}$ \\
\hline \multicolumn{2}{|c|}{ Fasting blood glucose (mmol/L) } & $8.25 \pm 0.77^{\mathrm{a}}$ & $12.89 \pm 1.13^{b}$ & $12.49 \pm 0.66^{b}$ & $9.61 \pm 0.59^{d}$ & $13.24 \pm 0.71^{b}$ & $11.57 \pm 0.84^{b}$ \\
\hline \multicolumn{2}{|c|}{ Serum insulin $(\mathrm{mU} / \mathrm{L})$} & $7.63 \pm 0.60^{a}$ & $12.01 \pm 0.96^{b}$ & $11.12 \pm 0.78^{b}$ & $8.75 \pm 0.80^{d}$ & $11.87 \pm 0.78^{b}$ & $10.26 \pm 0.58^{c}$ \\
\hline \multicolumn{2}{|c|}{ HOMIA-IR } & $2.76 \pm 0.21^{\mathrm{a}}$ & $6.85 \pm 0.74^{b}$ & $6.16 \pm 0.63^{b}$ & $3.82 \pm 0.31^{d}$ & $6.95 \pm 0.58^{b}$ & $5.22 \pm 0.50^{c}$ \\
\hline \multicolumn{2}{|r|}{ QUICKI } & $0.56 \pm 0.02^{a}$ & $0.45 \pm 0.00^{b}$ & $0.47 \pm 0.02^{b}$ & $0.52 \pm 0.01 \mathrm{~d}$ & $0.46 \pm 0.01^{b}$ & $0.47 \pm 0.01^{b}$ \\
\hline \multicolumn{2}{|r|}{$\begin{array}{l}\text { Blood glucose at } 0 \mathrm{~h} \\
(\mathrm{mmol} / \mathrm{L})\end{array}$} & $8.22 \pm 0.64^{a}$ & $13.57 \pm 0.90^{b}$ & $12.26 \pm 0.64^{b}$ & $9.33 \pm 0.68^{\mathrm{d}}$ & $13.30 \pm 0.77^{b}$ & $11.42 \pm 0.71^{\mathrm{c}}$ \\
\hline \multirow{4}{*}{ OGTT } & $\begin{array}{l}\text { Blood glucose at } 0.5 \mathrm{~h} \\
(\mathrm{mmol} / \mathrm{L})\end{array}$ & $12.24 \pm 0.79^{a}$ & $25.88 \pm 1.25^{b}$ & $24.25 \pm 0.79^{b}$ & $15.56 \pm 0.77^{\mathrm{d}}$ & $24.94 \pm 0.96^{b}$ & $22.15 \pm 0.87^{c}$ \\
\hline & $\begin{array}{l}\text { Blood glucose at } 1 \mathrm{~h} \\
(\mathrm{mmol} / \mathrm{L})\end{array}$ & $11.47 \pm 0.77^{\mathrm{a}}$ & $22.87 \pm 1.43^{b}$ & $20.04 \pm 0.51^{c}$ & $13.68 \pm 0.72^{d}$ & $22.51 \pm 0.76^{b}$ & $19.02 \pm 0.64^{c}$ \\
\hline & $\begin{array}{l}\text { Blood glucose at } 2 \mathrm{~h} \\
(\mathrm{mmol} / \mathrm{L})\end{array}$ & $8.53 \pm 0.60^{a}$ & $16.07 \pm 1.19^{b}$ & $14.17 \pm 0.71^{\mathrm{c}}$ & $11.85 \pm 0.64^{\mathrm{d}}$ & $15.72 \pm 0.84^{b}$ & $14.64 \pm 0.81^{c}$ \\
\hline & AUC OGTT & $21.04 \pm 1.67^{\mathrm{a}}$ & $41.52 \pm 3.21^{b}$ & $37.08 \pm 2.56^{c}$ & $26.30 \pm 1.81^{\mathrm{d}}$ & $40.54 \pm 3.06^{b}$ & $35.16 \pm 2.24^{c}$ \\
\hline \multirow{4}{*}{ IITT } & $\begin{array}{l}\text { Blood glucose at } 0 \mathrm{~h} \\
(\mathrm{mmol} / \mathrm{L})\end{array}$ & $8.27 \pm 0.45^{a}$ & $13.57 \pm 0.96^{b}$ & $12.51 \pm 0.80^{\mathrm{b}}$ & $9.53 \pm 0.58^{\mathrm{d}}$ & $13.17 \pm 0.86^{\mathrm{b}}$ & $11.60 \pm 0.56^{\mathrm{c}}$ \\
\hline & $\begin{array}{l}\text { Blood glucose at } 0.5 \mathrm{~h} \\
(\mathrm{mmol} / \mathrm{L})\end{array}$ & $6.09 \pm 0.38^{a}$ & $12.56 \pm 0.78^{b}$ & $11.66 \pm 0.73^{b}$ & $8.01 \pm 0.73^{d}$ & $12.42 \pm 0.85^{b}$ & $9.81 \pm 0.63^{c}$ \\
\hline & $\begin{array}{l}\text { Blood glucose at } 1 \mathrm{~h} \\
(\mathrm{mmol} / \mathrm{L})\end{array}$ & $5.19 \pm 0.42^{\mathrm{a}}$ & $12.13 \pm 0.87^{b}$ & $11.17 \pm 0.70^{b}$ & $7.30 \pm 0.69^{d}$ & $11.89 \pm 0.89^{b}$ & $9.38 \pm 0.66^{c}$ \\
\hline & $\begin{array}{l}\text { Blood glucose at } 2 \mathrm{~h} \\
(\mathrm{mmol} / \mathrm{L})\end{array}$ & $7.07 \pm 0.53^{a}$ & $12.80 \pm 0.95^{b}$ & $11.86 \pm 0.81^{b}$ & $8.42 \pm 0.61^{\mathrm{d}}$ & $12.55 \pm 0.78^{b}$ & $10.63 \pm 0.57^{c}$ \\
\hline & $\mathrm{AUC}_{\text {IITT }}$ & $12.54 \pm 1.83^{\mathrm{a}}$ & $25.17 \pm 2.26^{b}$ & $23.27 \pm 1.49^{b}$ & $16.07 \pm 0.26^{\mathrm{d}}$ & $24.70 \pm 1.70^{b}$ & $20.16 \pm 1.24^{c}$ \\
\hline \multicolumn{2}{|c|}{ Hepatic glycogen (mg/g) } & $11.59 \pm 0.98^{a}$ & $2.34 \pm 0.30^{b}$ & $3.17 \pm 0.25^{b}$ & $8.77 \pm 0.42^{d}$ & $2.88 \pm 0.57^{b}$ & $5.35 \pm 0.47^{c}$ \\
\hline \multicolumn{2}{|c|}{ Hepatic GP activities } & $4.58 \pm 0.51^{\mathrm{a}}$ & $12.46 \pm 0.73^{b}$ & $11.24 \pm 0.39^{b}$ & $8.08 \pm 0.34^{\mathrm{d}}$ & $11.61 \pm 0.53^{b}$ & $9.91 \pm 0.45^{c}$ \\
\hline \multicolumn{2}{|c|}{ Hepatic PK activities } & $20.44 \pm 1.97^{a}$ & $6.76 \pm 0.89^{b}$ & $7.25 \pm 0.83^{b}$ & $15.20 \pm 0.93^{\mathrm{d}}$ & $6.57 \pm 0.88^{b}$ & $9.57 \pm 0.60^{c}$ \\
\hline \multicolumn{2}{|c|}{ Hepatic HK activities } & $9.39 \pm 0.86^{\mathrm{a}}$ & $2.82 \pm 0.84^{b}$ & $3.35 \pm 0.93^{b}$ & $7.53 \pm 0.88^{d}$ & $3.04 \pm 0.75^{b}$ & $4.65 \pm 0.31^{\mathrm{c}}$ \\
\hline \multicolumn{2}{|c|}{ Hepatic G6Pase activities } & $3.67 \pm 0.24^{\mathrm{a}}$ & $9.45 \pm 0.83^{b}$ & $8.62 \pm 0.85^{b}$ & $5.14 \pm 0.77^{d}$ & $9.38 \pm 0.55^{b}$ & $7.13 \pm 0.70^{c}$ \\
\hline
\end{tabular}

Data are presented as mean \pm SD. Multiple comparisons were done using one way ANOVA. Acaudina molpadioides fucoidans, Am-FUC; Isostichopus badionotus fucoidans, Ib-LFUC; Thelenota ananas fucoidans, Ta-LFUC. Body weight gain was assessed using 12 mice. OGTT and IITT were assessed using 6 mice, respectively. The other parameters were assessed using the 6 mice treated with normal saline. Different lowercase letters represent significant difference $(p<0.05)$ compared between groups.
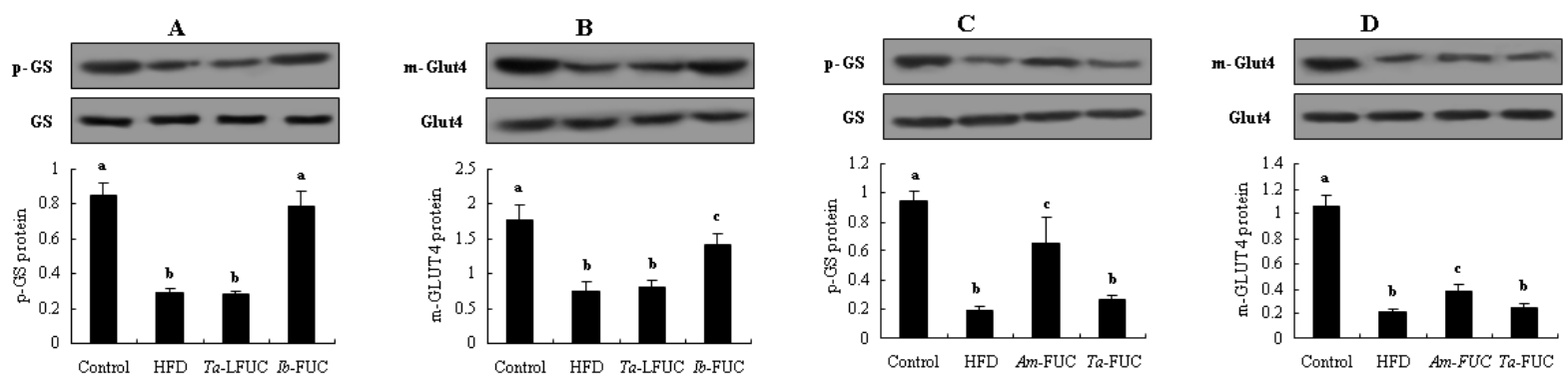

Figure 4. Comparatively analyzing the effects of between Ta-LFUC and $\mathrm{Ib}$-FUC (a similar molecular weight but different sulfation concentration), Ta-LFUC with sulfation at ortho-fucose and Am-FUC 
with sulfation at meta-position (quite molecular weight and sulfation concentration) on hepatic p-GS protein expression and skeletal muscle m-Glut4 protein expression in HFD-fed mice. Acaudina molpadioides fucoidans, Am-FUC; Isostichopus badionotus fucoidans, Ib-LFUC; Thelenota ananas fucoidans, Ta-LFUC. (A), p-GS protein expression (Ta-LFUC vs. Ib-FUC; p-GS and GS, 85 kDa); (B), m-Glut4 protein expression (Ta-LFUC vs. Ib-FUC; m-Glut4 and Glut4, $43 \mathrm{kDa}$ ); (C), p-GS protein expression (Ta-FUC vs. Am-FUC); (D), m-Glut4 protein expression (Ta-FUC vs. Am-FUC). p-GS protein was assessed using the 3 mice with $40 \mathrm{U} / \mathrm{kg}$ insulin stimulation while m-Glut4 protein as $0.5 \mathrm{U} / \mathrm{kg}$ insulin. Different lowercase letters represent significant difference $(p<0.05)$ compared between groups.

\subsection{Effects of Sulfation at Ortho-, or Meta-fucose Positions on Insulin Resistance}

In the prior experiments, without considering the effects of $\mathrm{M}_{\mathrm{W}}, \mathrm{Ht}$-FUC bioactivity, with higher $\mathrm{C}_{\mathrm{s}}$, was equated to $A m$-FUC bioactivity, with lower $\mathrm{C}_{\mathrm{s}}$. However, the activity of $I b$-FUC with higher $C_{\mathrm{s}}$ was superior to that of Ta-LFUC with lower $\mathrm{C}_{\mathrm{s}}$. These seemingly exhibited contradictory results. As shown in Figure 1, the structure of Ht-FUC had 2,4dual-sulfation (2,4DS) in fucose A, 2-sulfation (2S) in fucose C, and $2 S$ in fucose D, whereas $A m$-FUC had 2,4DS in fucose A and $2 S$ in fucose $C$, showing that there was one more $2 \mathrm{~S}$ in the fucose neighboring 2,4DS-fucose in $\mathrm{Ht}$-FUC than in $\mathrm{Am}$-FUC. The structure of $\mathrm{Ib}$-FUC had $2,4 \mathrm{DS}$ in fucose $\mathrm{A}, 2 \mathrm{~S}$ in fucose $\mathrm{B}$, and $2 \mathrm{~S}$ in fucose $\mathrm{C}$, whereas Ta-FUC had $2,4 \mathrm{DS}$ in fucose $A$ and $2 S$ in fucose $B$. There was one more $2 S$ in fucose spaced 2,4DS-fucose in $I b$-FUC than in Ta-FUC. In other words, the fucoses with sulfation in Am-FUC were metapositioned, while in Ta-FUC, they were ortho-positioned. Thus, we speculated that the contradictory results might be related to sulfation at ortho- or meta-fucose. The subsequent experiments were conducted to verify our speculation through comparative analysis of the effects of $A m$-FUC and Ta-FUC $\left(\mathrm{M}_{\mathrm{w}}, 1614.1 \pm 31.6\right.$ vs. $1380.0 \pm 8.1 \mathrm{kDa} ; \mathrm{C}_{\mathrm{s}}, 26.3 \pm 2.7 \mathrm{vs}$. $28.2 \pm 3.5 \%$, respectively) on insulin resistance alleviation.

As shown in Table 1, there were no significant differences in body weight gain, fasting blood glucose, serum insulin, HOMIA-IR, and QUICKI values between HFD and Ta-FUC groups, while body weight gain, serum insulin, and HOMIA-IR score were remarkably improved in the insulin-resistant mice when treated with Am-FUC $(p<0.05)$. With regards to OGTT and IITT, the blood glucose levels at all time points did not significantly differ between the Ta-FUC and HFD groups: similar findings were observed for AUC OGTT $_{\text {and }}$ AUC $_{\text {IITT }}$. In contrast, Am-FUC caused apparent decreases in blood glucose levels at all time points in OGTT and IITT compared with HFD-fed mice $(p<0.05)$, as well as distinct reductions in $\mathrm{AUC}_{\mathrm{OGTT}}$ and $\mathrm{AUC}_{\mathrm{IITT}}(p<0.05)$. Moreover, hepatic glycogen content and glucose metabolism-related enzyme activities were also unchanged in insulin-resistant mice when administrated with Ta-FUC. Comparatively, Am-FUC noticeably enhanced glycogen content and PK and HK activities, and inhibited GP and G6Pase activities in the liver of HFD-fed mice $(p<0.05)$. Furthermore, as shown in Figure 4C,D, Am-FUC caused significant increases in $\mathrm{p}-\mathrm{GS}$ protein expression in the liver and $\mathrm{m}-\mathrm{Glut} 4$ protein in the skeletal muscle of insulin-resistant mice ( $p<0.05)$, while Ta-FUC had no effect. These results visibly showed that $A m$-FUC could improve insulin resistance while Ta-FUC could not, indicating that sulfation at meta-fucose is essential for fucoidans to alleviate insulin resistance.

\subsection{Effects of 2-O-Sulfation or 4-O-Sulfation on Insulin Resistance}

Sulfation site may affect fucoidan activity. Thus, we investigated the effects of $\mathrm{Am}$ LFUC3 (with a 2-O-sulfation; $\mathrm{M}_{\mathrm{w}}, 327.2 \pm 12.5 \mathrm{kDa} ; \mathrm{C}_{\mathrm{s}}, 26.8 \pm 2.6 \%$ ) and $\mathrm{Pg}$-FUC (with a 4-O-sulfation; $\mathrm{M}_{\mathrm{w}}, 310.5 \pm 26.8 \mathrm{kDa} ; \mathrm{C}_{\mathrm{s}}, 27.4 \pm 2.5 \%$ ) on insulin resistance. As shown in Figure 5, both $A m$-LFUC3 and Pg-FUC significantly lowered body weight gain (by 36.02 vs. $43.33 \%$ ), fasting blood glucose (by 21.02 vs. $28.01 \%$ ), serum insulin (by 24.81 vs. 31.39\%), HOMIA-IR value (by 41.12 vs. 51.24\%), and enhanced QUICKI score (by 15.56 vs. $17.78 \%$, respectively) compared with HFD-fed mice. Similarly, Am-LFUC3 and Pg-FUC obviously enhanced glucose tolerance and insulin tolerance, showing AUC OGTT 30.52 vs. $41.22 \%$, and $\mathrm{AUC}_{\text {IITT }} 31.88$ vs. $43.52 \%$. Alhough there were no significant differences in 
the aforementioned parameters between the two groups, the $P g$-FUC group data were more tended towards that of the control group more than that of the Am-LFUC3 group. In the liver tissue, Am-LFUC3 and Pg-FUC remarkably elevated hepatic glycogen contents (2.43- vs. 3.09-fold), PK activities (1.00- vs. 1.45-fold), and HK activities (1.37- vs. 1.98-fold), while the two fucoidans decreased GP activities (33.87 vs. $45.26 \%$ ) and G6Pase (40.53 vs. $52.28 \%$, respectively). Western blotting results showed that $A m$-LFUC3 and $P g$-FUC caused p-GS protein expression increases by 2.01 - and 3.88-fold, respectively, in the liver of insulin-resistant mice, as well as m-Glut4 protein expression increases by $1.00-$ and 1.67-fold, respectively, in skeletal muscle. Interestingly, PK and HK activities, p-GS and m-Glut4 protein expressions in the $P g$-FUC group were remarkably elevated compared with these parameters in the Am-LFUC3 group $(p<0.05)$. The aforementioned results showed that the bioactivity of $P g$-FUC were superior to that of $A m$-LFUC3, suggesting that fucoidans with 4-O-sulfation make a higher contribution to insulin resistance alleviation than fucoidans with 2-O-sulfation.
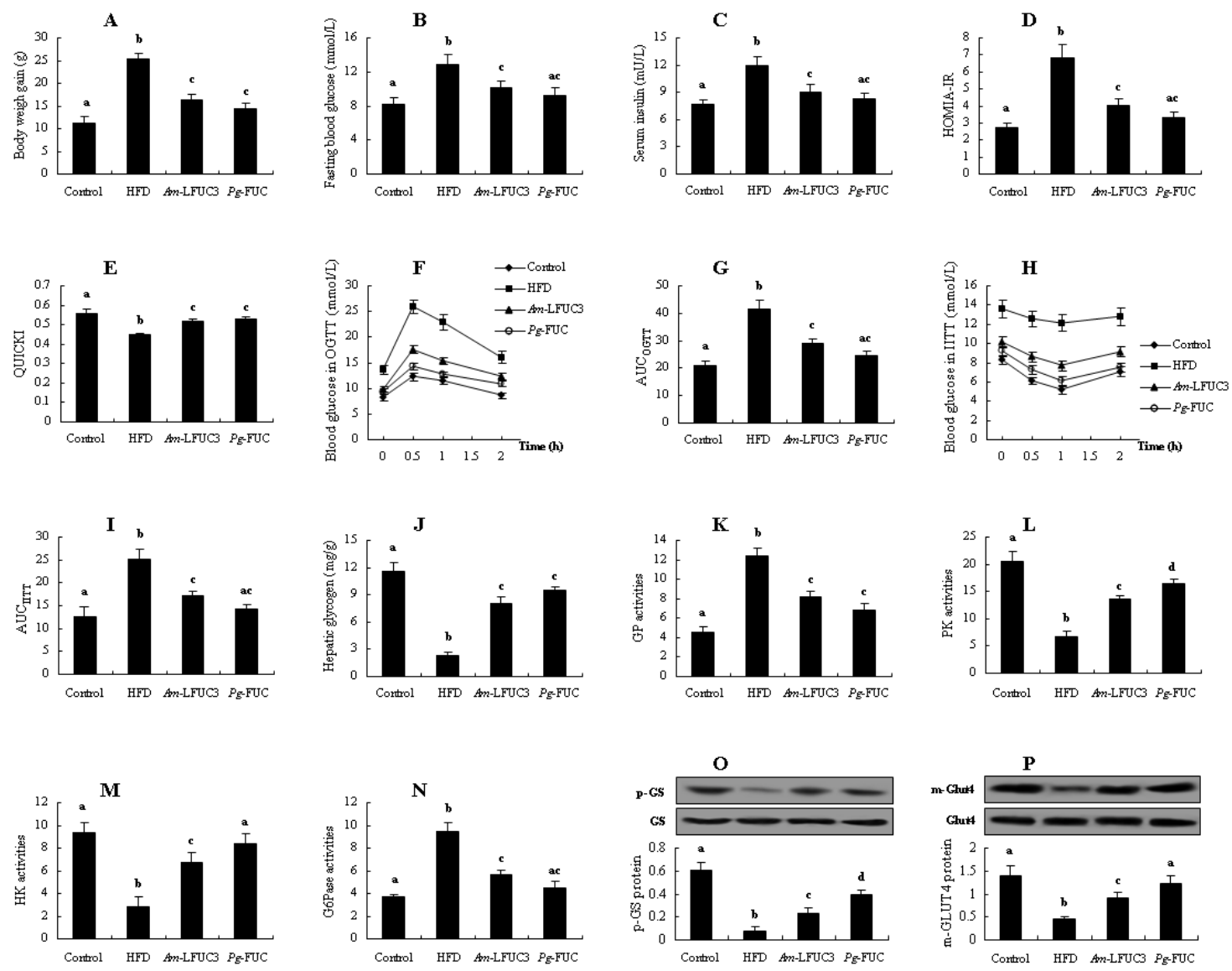

Figure 5. Comparatively analyzing the effects of between $A m$-LFUC3 with 2-O-sulfation and $P g$-FUC with 4-O-sulfation (quite molecular weight and sulfation concentration) on alleviating insulin resistance in HFD-fed mice. Acaudina molpadioides fucoidans, Am-FUC; Pearsonothuria graeffei fucoidans, Pg-LFUC. (A), Body weight gain; (B), Fasting blood glucose; (C), Serum insulin; (D), HOMIA-IR value; (E), QUICKI score; (F), OGTT test; (G), AUC in OGTT test; (H), IITT test; (I), AUC in IITT test; (J), Hepatic glycogen; (K), GP activities; (L), PK activities; (M), HK activities; (N), G6Pase activities; (O), p-GS protein expression (p-GS and GS, $85 \mathrm{kDa}$ ); (P), m-Glut4 protein expression (m-Glut4 and Glut4, $43 \mathrm{kDa}$ ). Body weight gain was assessed using 12 mice. OGTT and IITT were assessed using 6 mice, respectively. p-GS protein was assessed using the 3 mice with $40 \mathrm{U} / \mathrm{kg}$ insulin stimulation while $\mathrm{m}$-Glut 4 protein as $0.5 \mathrm{U} / \mathrm{kg}$ insulin. The other parameters were assessed using the 6 mice treated with normal saline. Different lowercase letters represent significant difference $(p<0.05)$ compared between groups. 


\section{Discussion}

Our previous studies also indicated that fucoidans derived from Acaudina molpadioides and Isostichopus badionotus could improve insulin resistance [18,19,24]. However, Wright et al. found that there were no significant changes in insulin resistance parameters in obese humans aged between 18 and 65 years when treated with $500 \mathrm{mg}$ fucoidans per day for 90 days [25]. Taken together, these studies imply that different fucoidans may exert different effects on insulin resistance. However, it was unclear which fucoidan structures or functional groups influenced the observed effects. In the present study, we investigated the role of the structure-activity relationship of SC-FUC in improving in insulin resistance. Our data indicated that low $\mathrm{M}_{\mathrm{w}}$, high $\mathrm{C}_{\mathrm{s}}$, sulfation at meta-fucose, and 4-O-sulfation were beneficial for improving insulin resistance.

$\mathrm{M}_{\mathrm{W}}$ of fucoidans has been reported to be related to their biological activities. Fucoidans with lower $\mathrm{M}_{\mathrm{w}}$ have certain advantages over those with higher $\mathrm{M}_{\mathrm{w}}$ due to their improved diffusion into biological tissues and the bloodstreams [12]. Zhu et al. reported that the anti-obesity activity of depolymerized sulfated polysaccharides $(14.3 \mathrm{kDa})$ from the sea cucumber, Stichopus japonicus, was more effective than that of polysaccharides (fucoidans $>670 \mathrm{kDa}$ ) in HFD-fed mice [26]. These depolymerized sulfated polysaccharides were more amenable to decreasing fat accumulation than sulfated polysaccharides, but body weight gain and insulin resistance parameters (such as $\mathrm{AUC}_{\text {OGTT }}$ and HOMIA-IR) did not change significantly between the two groups. Yang et al. reported that the anticancer activity of fucoidans could be significantly enhanced by lowering their $\mathrm{M}_{\mathrm{w}}$ [27]. In the present study, although there were no significant changes in fasting blood glucose, serum insulin, and $\mathrm{AUC}_{\mathrm{IITT}}$ between $\mathrm{Am}$-FUC and $\mathrm{Am}$-LFUCs groups, a remarkable increase in QUICKI and reductions in body weight gain, $\mathrm{AUC}_{\mathrm{OGTT}}$, and HOMIA-IR were apparent in Am-LFUC4-treated animals compared with $A m$-FUC-fed mice. Similar changes were exhibited in several insulin resistance parameters in the liver of HFD-fed mice. These demonstrated that $\mathrm{M}_{\mathrm{W}}$ could affect SC-FUC activity, lower $\mathrm{M}_{\mathrm{W}}$ of SC-FUC with stronger effects on improving insulin resistance. Fucoidan activity became increasingly apparent as $\mathrm{M}_{\mathrm{w}}$ decreased.

Nonetheless, some reports contradict our findings. Xu et al. reported that Ta-FUC and their depolymerized derivatives could significantly prevent ethanol-induced gastric ulcers, including anti-oxidations and anti-inflammation, but there were no significant changes between Ta-FUC (1380.0 kDa) and Ta-LFUCs (828.7, 483.0, and $215.0 \mathrm{kDa})$ [16]. In the present study, we also investigated the effects of $\mathrm{Ta}$-FUC on alleviating insulin resistance, and the results showed no biological activity of the fucoidans in HFD-fed mice. Fucoidans derived from brown algae with different $\mathrm{M}_{\mathrm{w}}$ were also had their bioactivities investigation. In contrast to our results, the relationship between the $\mathrm{M}_{\mathrm{w}}$ of fucoidans and their antioxidant or epithelial-mesenchymal transition activities is not simply linear. These discrepancies may result from fucoidans isolated from the different species and different $M_{W}$ distributions (this study $\mathrm{M}_{\mathrm{w}} 140-1600 \mathrm{kDa}$, fucoidans from brown alga $\mathrm{M}_{\mathrm{w}} 1-60 \mathrm{kDa}$ ) [28,29].

Sulfation is a critical determinant of fucoidan bioactivity, involving both the $\mathrm{C}_{S}$ and sulfate position. Considering similar $\mathrm{M}_{\mathrm{w}}$ but varying $\mathrm{C}_{\mathrm{S}}$ in $\mathrm{Am}$-FUC and $\mathrm{Ht}$-FUC, we comparatively analyzed their effects to investigate the influence of $C_{S}$ influence. The $C_{S}$ of $\mathrm{Ht}$-FUC was higher than that of $\mathrm{Am}$-FUC ( $\mathrm{Ht}$-FUC having one more sulfate at fucose $\mathrm{A}$ ), but the effects of $\mathrm{Ht}$-FUC on improving insulin resistance were not superior to those of $\mathrm{Am}$ FUC. This seemingly implied that $C_{S}$ did not play a crucial role in the ability of fucoidans to alleviate insulin resistance. However, several studies opposed to these findings. For example, Li et al. reported that fucoidans from Sargassum fusiforme with $47.5 \mathrm{kDa} \mathrm{M}_{\mathrm{w}}$ and $20.8 \% C_{S}$ exerted an inhibitory effect on HMEC- 1 cell angiogenesis. However, the lower $C_{S}$ fractions $\left(7.5 \% \mathrm{C}_{\mathrm{S}}\right.$ and $\left.12.4 \mathrm{kDa} \mathrm{M}_{\mathrm{W}}\right)$ had no effect [30]. The over-sulfation of fucoidans through chemical modification resulted in a stronger inhibition of cancer cell growth and angiogenesis [31,32]. All these papers vehemently suggested the importance of fucoidan $C_{S}$ on their bioactivity, which conflicted with our aforementioned results. To clarify whether $\mathrm{C}_{S}$ of SC-FUC could affect insulin-resistant activity, further investigations were conducted 
using Ta-LFUC and $I b$-FUC. The two fucoidans have similar $\mathrm{M}_{\mathrm{w}}$, but $I b$-FUC had a higher $C_{S}$. Ta-LFUC failed to improve HFD-induced insulin resistance. Comparatively, Ib-FUC significantly mitigated insulin resistance. These results implied that higher $C_{S}$ might be beneficial for fucoidans in improving insulin resistance.

Exclusive $\mathrm{M}_{\mathrm{w}}$ influence, sulfation position would be the only explanation for our observed findings. $\mathrm{C}_{\mathrm{S}}$ was higher in $\mathrm{Ht}$-FUC than in $\mathrm{Am}$-FUC, because there was one more sulfate substitution in the fucose neighboring 2,4DS-fucose in $\mathrm{Ht}$-FUC, unlike in $\mathrm{Am}$-FUC. Considering the similar bioactivities of $\mathrm{Ht}$-FUC and $\mathrm{Am}$-FUC, it was speculated that the $2 \mathrm{~S}$ in the fucose neighboring 2,4DS-fucose was dispensable for fucoidan bioactivity. On the other hand, Ib-FUC possessed one more sulfation, located in the fucose spaced 2,4DS-fucose compared with Ta-FUC. The effects of $I b$-FUC were superior to those of Ta-LFUC. Thus, $2 \mathrm{~S}$ in fucose spaced 2,4DS-fucose might be indispensable for fucoidans to improve insulin resistance. To confirm the hypothesis, the bioactivities of $\mathrm{Am}$-FUC (with meta-fucose sulfate substitution) and $\mathrm{Ta}$-FUC (with ortho-fucose sulfate substitution) were compared. All the insulin resistance-related parameters indicated that $\mathrm{Am}$-FUC bioactivity exceeded that of $\mathrm{Ta}$-FUC. These observations demonstrated that sulfation at meta-fucose was vital for SCFUC insulin resistance-alleviating effect. However, it is regrettable that there are currently no relevant studies to support our conclusion.

2-O-sulfation and 4-O-sulfation were identified in SC-FUC. Recently, researches have reported that the 4-O-sulfation substitution pattern in SC-FUC exhibited more potent effects on anti-inflammatory and anti-hyperlipidemia activities [22,33]. The authors comparatively investigated the bioactivities of $I b$-FUC and $P g$-FUC, and found that the effects of $P g$-FUC with 4-O-sulfation were stronger than those of $I b$-FUC with 2-O-sulfation. However, the $\mathrm{C}_{\mathrm{S}}$ in the two SC-FUC were not similar because there was one more 2-O-sulfation in the fucose neighboring 2,4DS-fucose in Ib-FUC than in Pg-FUC. Therefore, the consequences could be controversial.

In the present study, the effects of Ib-FUC and Am-LFUC3 on alleviating insulin resistance were contrastively determined. The two fucoidans have the same $\mathrm{M}_{\mathrm{W}}$ and $\mathrm{C}_{\mathrm{S}}$, while the difference was 4-O-sulfation in Pg-FUC and 2-O-sulfation in Am-LFUC3. PK and $\mathrm{HK}$ activities and p-GS and m-Glut4 protein expressions were considerably improved in the $\mathrm{Pg}$-FUC group than in the $\mathrm{Am}$-LFUC3 group. Moreover, there were no significant differences in the other insulin resistance-related parameters between the two SC-FUC groups, but the data of the $P g$-FUC group were closer to those of the control group. The greater effects of $P g$-FUC (vs. Am-LFUC3) indicated that 4-O-sulfation in SC-FUC was more favorable for insulin resistance mitigation than 2-O-sulfation. Several researches supported our results. For instance, $\mathrm{Li}$ et al. stated that the 4-O-sulfated structure of $\mathrm{Pg}$-FUC might be the primary functional group to treat with metabolic syndromes [34]. Additionally, Mandal et al. founded that sulfate groups located at C-4 of $(1 \rightarrow 3)$-linked fucopyranosyl units (4-O-sulfation) appeared to be especially important for the anti-herpetic activity of brown seaweed fucoidans [35]. Fereira et al. indicated that both 2,4-di-O-sulfation and signal 4-O-sulfation of fucoidans had a distinguished potent anticoagulant activity, while exclusively 2-O-sulfation of fucoidans was almost devoid of activity [36]. Fonseca et al. also proved the importance of 2,4-di-O-sulfation in fucoidans with anticoagulant activity [37]. On the contrary, Chevolot et al. reported that anticoagulant activity was greatly magnified upon treatment with fucoidans containing 2-O-sulfation and 3-O-sulfation [38].

\section{Materials and Methods}

\subsection{Preparation of Fucoidans}

Dried sea cucumbers, Acaudina molpadioides (Am), Isostichopus badionotus (Ib), Thelenota ananas (Ta), Holothuria tubulosa $(\mathrm{Ht})$, and Pearsonothuria graeffei $(\mathrm{Pg})$ were procured from marine product markets in Zhoushan, China. The species were identified by Professor Laijin Su of Wenzhou University (Wenzhou, China). Fucoidans were prepared as previously reported [13]. Their structures, $M_{W}$, and $C_{s}$ are shown in Figure $1[33,39]$. 


\subsection{Low- $M_{w}$ Fucoidans Preparation}

Different low- $\mathrm{M}_{\mathrm{w}}$ fucoidans from Acaudina molpadioides (Am-LFUC) were obtained according to the method described by Yu et al [23]. Briefly, the intracellular enzyme Flavobacteriaceae CZ1127 (from marine bacterial stain W. fucanilytica) was added to an AmFUC solution $(20 \mathrm{mmol} / \mathrm{L}$ Tris- $\mathrm{HCl}$ and $0.3 \mathrm{~mol} / \mathrm{L} \mathrm{NaCl})$ for enzymatic hydrolysis at $37^{\circ} \mathrm{C}$ for $5,7,9$, and $11 \mathrm{~h}$. After thermal inactivation at $100^{\circ} \mathrm{C}$, the enzymatic solution was filtered through a Sephacryl S-300/400/500 column to collect the purified Am-LFUC. Their average $\mathrm{M}_{\mathrm{W}}$ were determined by high performance size exclusion chromatography-multiangle laser light scattering (HPSEC-MALLS), which consisted of HPLC, refractive index detection (Agilent 1260, Aglient, Santa Clara, CA, USA), 18-angle laser light scattering instrument (Dawn HELEOS, Wyatt, SB, USA), and SEC column. The mobile phase was $0.1 \mathrm{M} \mathrm{Na}_{2} \mathrm{SO}_{4}$. The $C_{S}$ were determined using a Dionex IC-2000 ion chromatography (Dionex, Sunnyvale, CA, USA). Briefly, after hydrolysis with trifluoroacetic acid and drying under vacuum, $20 \mu \mathrm{L}$ fucoidan hydrolysate was injected into the ion chromatograph to determine the conductivity signal. The chromatographic system included a Shodex IC SI-90E separation column (250 mm $\times 4.6 \mathrm{~mm}$; Showa Denko America, Inc., New York, NY, USA), and the eluent was $1 \mathrm{mM} \mathrm{Na}_{2} \mathrm{CO}_{3}+4 \mathrm{mM} \mathrm{NaHCO}_{3}$ with $2.5 \%$ acetone. A standard sulfate was used to quantify the sulfate content of fucoidans according to the peak area. In these experiments, we collected four different $A m$-LFUC with $\mathrm{M}_{\mathrm{W}}$ and $\mathrm{C}_{\mathrm{s}}$ as follows: $A m$-LFUC1 $\left(\mathrm{M}_{\mathrm{W}} 847.5 \pm 22.4 \mathrm{kDa}, \mathrm{C}_{\mathrm{s}} 26.6 \pm 1.8 \%\right), A m$-LFUC2 $\left(\mathrm{M}_{\mathrm{W}} 530.9 \pm 13.0 \mathrm{kDa}, \mathrm{C}_{\mathrm{s}} 27.1 \pm 2.5 \%\right)$, Am-LFUC3 $\left(\mathrm{M}_{\mathrm{w}} 327.2 \pm 12.5 \mathrm{kDa}, \mathrm{C}_{\mathrm{s}} 26.8 \pm 2.6 \%\right)$, and Am-LFUC4 $\left(\mathrm{M}_{\mathrm{w}} 142.4 \pm 13.3 \mathrm{kDa}\right.$, $\mathrm{C}_{\mathrm{s}} 27.2 \pm 2.8 \%$ ). Am-FUC and the depolymerized $\mathrm{Am}$-LFUC had the similar sulfate contents, indicating that sulfate groups were not hydrolyzed during degradation.

Using the foregoing methods, Ta-FUC was subjected to enzymolysis using Flavobacteriaceae CZ1127 for $10 \mathrm{~h}$, and a low $\mathrm{M}_{\mathrm{W}} \mathrm{Ta}$-FUC (Ta-LFUC) was finally obtained with $\mathrm{M}_{\mathrm{W}}$ and $\mathrm{C}_{\mathrm{s}}$, of $450.7 \pm 15.1 \mathrm{kDa}$ and $28.4 \pm 3.9 \%$, respectively. Yu et al. have proved that structural features of $\mathrm{Ta}-\mathrm{FUC}$ were retained during enzymatic degradation [23].

\subsection{Animal Experiments}

Male C57BL/6J mice (licensed ID: SCXK2019-0001), 16-18 g, were purchased from Vital River Laboratory Animal Center (Beijing, China). The mice were kept in a stable environment under a 12-h light/dark cycle daily throughout the experiment. The mice (144 in total and 12 animals in each group) were assigned to 12 groups: control group (normal chow diet feeding: $70 \%$ carbohydrate, $20 \%$ protein, and $10 \%$ fat), HFD group (HFD feeding: $29 \%$ carbohydrates, $16 \%$ protein, and $55 \%$ fat), and 10 experiment groups (administered with HFD as well as $40 \mathrm{mg} / \mathrm{kg}$ of 5 types of fucoidans, 4 types of $A m$-LFUC, or Ta-LFUC intragastrically, $0.2 \mathrm{~mL}$ daily). Animal experiments were conducted for $12 \mathrm{w}$. At $11 \mathrm{w}$ of feeding, an oral glucose tolerance test (OGTT, six mice per group) and an intraperitoneal insulin tolerance test (IITT, six mice per group) were conducted. At $12 \mathrm{w}$ of administration, all mice were sacrificed. Blood was collected to test insulin resistance-related parameters. The liver and skeletal muscle tissues were collected for further study.

Firstly, Am-FUC and the 4 depolymerized Am-LFUCs groups were used to analyze the activities of different $\mathrm{M}_{\mathrm{w}}$ fucoidans. Secondly, we investigated the influence of different $\mathrm{C}_{\mathrm{S}}$ fucoidans using comparative analysis in between $\mathrm{Am}$-FUC and $\mathrm{Ht}$-FUC groups, and $T a$-LFUC and $I b$-FUC groups (they have different $C_{\mathrm{s}}$ while similar $\mathrm{M}_{\mathrm{W}}$ ). Subsequently, to clarify the effects of sulfation at ortho- or meta-fucose, a comparative analysis was studied in between $A m$-FUC and Ta-FUC groups (they have similar $\mathrm{M}_{\mathrm{W}}$ and $\mathrm{C}_{\mathrm{S}}$, but sulfation at ortho-fucose in Ta-FUC and sulfation at meta-fucose in $\mathrm{Am}$-FUC). Finally, we investigated the different effects of 2-O-sulfation and 4-O-sulfation using $\mathrm{Am}$-LFUC3 and $\mathrm{Pg}$-FUC groups (they have similar $\mathrm{M}_{\mathrm{W}}, \mathrm{C}_{\mathrm{s}}$, and sulfation at meta-fucose, while a 2-O-sulfation in Am-LFUC3 and 4-O-sulfation in $\mathrm{Pg}$-FUC). 


\subsection{OGTT and IITT}

At $11 \mathrm{w}$ of treatment, 5-h fasted mice were intragastrically administered with $2 \mathrm{~g} / \mathrm{kg}$ glucose, and blood glucose was measured using a commercial kit (Biosino, Beijing, China) at $0,0.5,1$, and $2 \mathrm{~h}$ for OGTT (six mice per group). Similarly, another six mice were intraperitoneally injected with $0.5 \mathrm{U} / \mathrm{kg}$ insulin, and blood glucose was measured at the aforementioned time points. Equation (1) was used to calculate the areas under the curve of OGTT (AUC $\mathrm{OGTT}$ ) and IITT $\left(\mathrm{AUC}_{\text {IITT }}\right)$ [40].

$$
\mathrm{AUC}_{\mathrm{OGTT}} / \mathrm{AUC}_{\mathrm{IITT}}=0.25 \times \mathrm{A}+0.5 \times \mathrm{B}+0.75 \times \mathrm{C}+0.5 \times \mathrm{D}
$$

where A, B, C, and D represent blood glucose level at $0,0.5,1$, and $2 \mathrm{~h}$ after treating with glucose or insulin, respectively.

\subsection{Insulin Stimulation and Plasma Membrane Preparation}

At the end of the animal experiments, the mice were sacrificed after treatment with normal saline (six mice in each group) or insulin stimulation for p-GS protein (three animals per group) and plasma membrane Glut 4 (m-Glut4) protein (three animals each). Briefly, 5 min after intraperitoneal injection with $40 \mathrm{U} / \mathrm{kg}$ insulin, the mice were sacrificed to collect the liver tissue to measure p-GS protein. Meanwhile, another three mice were sacrificed $30 \mathrm{~min}$ after $0.5 \mathrm{U} / \mathrm{kg}$ insulin injection, and the skeletal muscle was collected to measure $\mathrm{m}$-Glut4 protein.

Plasma membrane from skeletal muscle was extracted according to our previous study [41]. Briefly, skeletal muscle from the $0.5 \mathrm{U} / \mathrm{kg}$ insulin-injected mice was homogenized to extract the crude membrane through triple centrifugation at 1200,9000 , and $19,000 \times g$. A sucrose density-gradient $(25,32$, and $35 \%)$ centrifugation at $150,000 \times g$ for $16 \mathrm{~h}$ was carried out to separate the plasma membrane. The $25 \%$ sucrose fraction was collected and centrifuged at $190,000 \times g$ for $1 \mathrm{~h}$ to obtain the Glut 4 protein at m-Glut4.

\subsection{Blood Glucose and Plasma Insulin Analysis}

At the end of animal experiments, the mice were sacrificed to collect blood. Fasting blood glucose levels were determined using glucose testing kits (Biosino, Beijing, China), and serum insulin levels were determined using insulin ELISA kits (Invitrogen, Carlsbad, CA, USA). Equations (2) and (3) were used to calculate the homeostasis model assessment of insulin resistance index (HOMA-IR) and quantitative insulin sensitivity check index (QUICKI), respectively [42].

$$
\begin{gathered}
\text { HOMA-IR }=(\text { fasting blood glucose } \times \text { serum insulin }) / 22.5 \\
\text { QUICKI }=1 /[\log (\text { fasting blood glucose })+\log (\text { serum insulin })
\end{gathered}
$$

\subsection{Hepatic Glycogen Content Detection}

The liver tissues $(0.1 \mathrm{~g})$ were homogenized using $4 \mathrm{M} \mathrm{NaOH}$ and heated in boiling water. After diluting with distilled water, the homogenate was centrifuged to collect the pellet. Hepatic glycogen content was determined form the pellet dissolved in $1.5 \mathrm{~mL}$ distilled water using a commercial kit (Jiancheng, Nanjing, Jiangsu, China).

\subsection{Glucose Metabolism Enzymes Test}

The activities of glucose metabolism-related enzymes, including GP, PK, HK, and G6Pase in the liver of normal saline-treated mice, were assayed according to our previous study's method [16]. Briefly, HK, PK, and GP activities were determined using liver homogenate in Tris- $\mathrm{HCl}$ (Ph 7.4), while G6Pase activity was determined in HCl-imidazole ( $\mathrm{pH}$ 6.5). Total protein content was determined using a commercial kit (Biosino). HK activity was determined using glucose 6-phosphate dehydrogenase, PK activity using L-phosphate dehydrogenase, GP using phosphoglucomutase and glucose-6-phosphatase, G6Pase using mutarotase and dehydrogenase. After reacting at $37^{\circ} \mathrm{C}$ for $2 \mathrm{~min}$, the system 
was tested for OD values at $340 \mathrm{~nm}$. The enzyme activities were calculated according to Equation (4) [24].

Enzyme activities $=\mathrm{OD}_{340 \mathrm{~nm}}$ every minute $/(6.22 \times$ total protein content $)$

\subsection{Western Blotting}

The liver and skeletal muscle tissues stimulated using 40 and $0.5 \mathrm{U} / \mathrm{kg}$ insulin, respectively, were homogenized in IP lysis buffer. The proteins, including m-Glut4 protein, were separated using 10\% SDS-PAGE and subsequently electro-transferred onto PVDF membranes. The membranes were incubated with diluted Glut4 (1:500), p-GS (1:200), or GS (1:200) antibodies (Cell Signaling, Danvers, MA, USA), followed by incubation with HRP conjugated IgG antibody. The bands were visualized using an ECL kit. Normalization of p-GS and m-Glut4 protein expressions were controlled by total GS and Glut4 protein.

\subsection{Statistical Analysis}

Data were evaluated using a one-way analysis of variance followed by Duncan's test using SPSS version 17.0 (SPSS Inc., Chicago, IL, USA). Values of $p<0.05$ were considered statistically significant.

\section{Conclusions}

The present study clarified the structure-activity relationship of SC-FUC in ameliorating insulin resistance in HFD-fed mice (Figure 6). SC-FUC with lower $\mathrm{M}_{\mathrm{w}}$ can more effectively mitigate insulin resistance than polysaccharides with larger $M_{w}$. Higher $C_{S}$ contribute more to SC-FUC bioactivity. Sulfation position is vital for SC-FUC in mitigating insulin resistance, showing that meta-fucose of sulfate substitution is superior to ortho-fucose, and 4-O-sulfation is more potent than 2-O-sulfation.

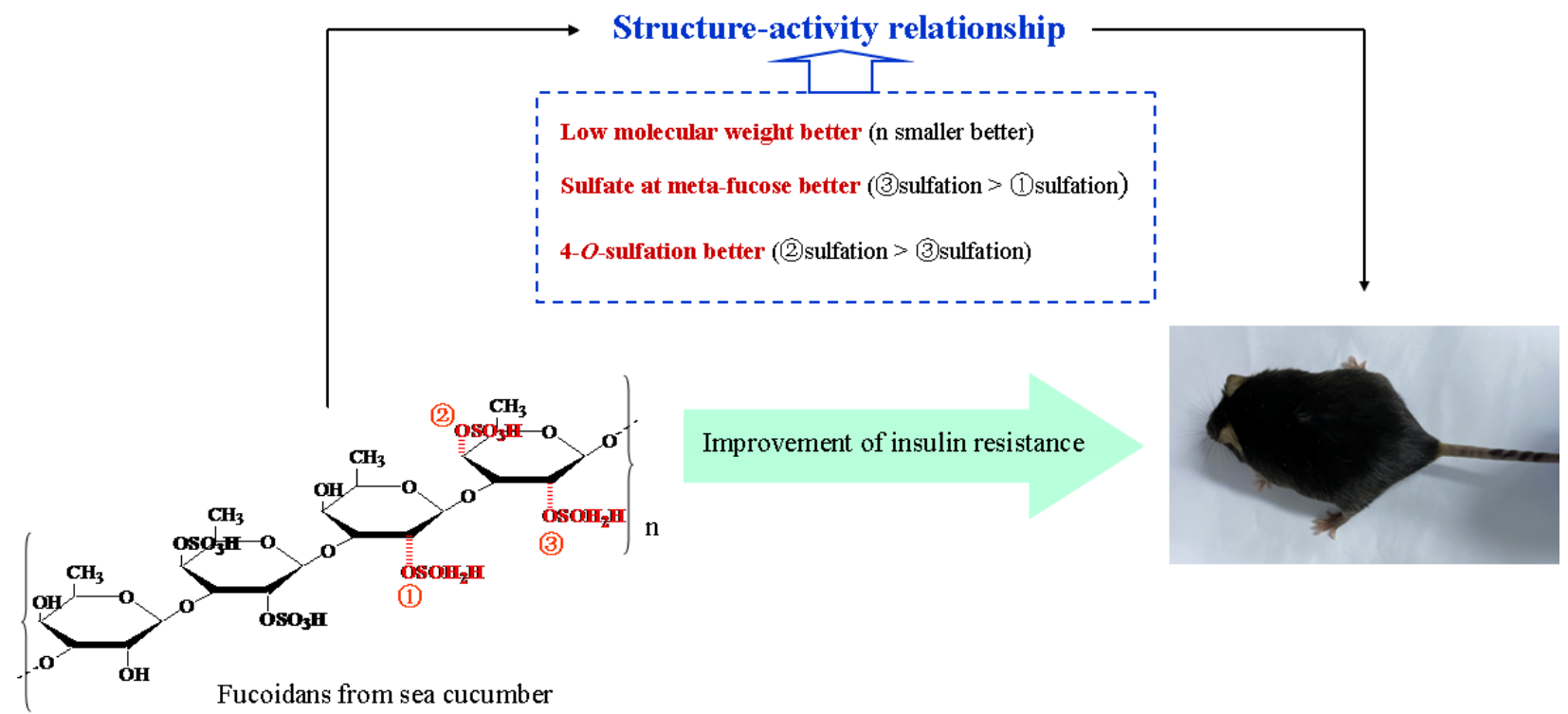

Figure 6. The structure-activity relationship of fucoidans from sea cucumber on improvement of insulin resistance. Our data showed that low molecular, sulfate at meta-fucose, and 4-O-sulfation played a significant part in the insulin resistant alleviation of fucoidans in mice.

Author Contributions: Conceptualization, S.H., X.G. and L.S.; methodology, S.C., H.Z. and M.D.; software, W.J. and Y.L.; validation, S.H., S.C., H.Z., M.D., W.J., Y.L., X.G., L.S. and Y.X.; formal analysis, Y.X.; investigation, M.D.; resources, S.H., W.J., Y.L., X.G. and L.S.; data curation, L.S.; writing-original draft preparation, S.H.; writing—review and editing, S.C., H.Z., M.D., W.J., Y.L., X.G., L.S. and Y.X.; visualization, M.D.; supervision, L.S. and X.G.; project administration, S.H.; funding acquisition, S.H., W.J., Y.L., X.G. and L.S. All authors have read and agreed to the published version of the manuscript. 
Funding: This research was supported by Natural Science Foundation of China (41806182), Zhejiang Provincial Universities and Research Institutes (2021JZ004 and 2019J00042), Public Projects of Zhejiang Province (LGN19D060001, LGN19C200017, and LGN20C200003), Open project program of Wenzhou characteristic food resources engineering technology research center (ZD202003-2), and Zhoushan Science and Technology Project (2020C21020 and 2018C21011).

Institutional Review Board Statement: This study was approved by the Ethics Committee of Qingdao University (No. 20191023C5714420200115018).

Informed Consent Statement: Not applicable.

Conflicts of Interest: The authors declare no conflict of interest.

\section{References}

1. Saravanakumar, K.; Park, S.; Sathiyaseelan, A.; Kim, K.; Cho, S.; Mariadoss, A.V.A.M.; Wang, M. Metabolite profiling of methanolic extract of gardenia jaminoides by LC-MS/MS and GC-MS and its anti-diabetic, and anti-oxidant activities. Pharmaceuticals 2021, 14, 102. [CrossRef] [PubMed]

2. Ren, L.; Zhou, X.; Huang, X.; Wang, C.; Li, Y. The IRS/PI3K/Akt signaling pathway mediates olanzapine-induced hepatic insulin resistance in male rats. Life Sci. 2019, 217, 229-236. [CrossRef]

3. Bao, S.; Wu, Y.L.; Wang, X.; Han, S.; Cho, S.; Ao, W.; Nan, J.X. Agriophyllum oligosaccharides ameliorate hepatic injury in type 2 diabetic $\mathrm{db} / \mathrm{db}$ mice targeting INS-R/IRS-2/PI3K/AKT/PPAR-gamma/Glut4 signal pathway. J. Ethnopharmacol. 2020, 257, 112863. [CrossRef]

4. Zhang, H.; Hui, J.; Yang, J.; Deng, J.; Fan, D. Eurocristatine, a plant alkaloid from Eurotium cristatum, alleviates insulin resistance in $\mathrm{db} / \mathrm{db}$ diabetic mice via activation of PI3K/AKT signaling pathway. Eur. J. Pharmacol. 2020, 887, 173557. [CrossRef]

5. Cao, C.; Li, C.; Chen, Q.; Huang, Q.; Pérez, M.E.M.; Fu, X. Physicochemical characterization, potential antioxidant and hypoglycemic activity of polysaccharide from Sargassum pallidum. Int. J. Biol. Macromol. 2019, 138, 1009-1017. [CrossRef]

6. Subash-Babu, P.; Ignacimuthu, S.; Alshatwi, A.A. Nymphayol increases glucose-stimulated insulin secretion by RIN-5F cells and GLUT4-mediated insulin sensitization in type 2 diabetic rat liver. Chem. Biol. Interact. 2015, 226, 72-81. [PubMed]

7. Barazzoni, R.; Gortan Cappellari, G.; Ragni, M.; Nisoli, E. Insulin resistance in obesity: An overview of fundamental alterations Eat. Weight Disord. 2018, 23, 149-157. [CrossRef] [PubMed]

8. Saravanakumar, K.; Park, S.; Mariadoss, A.V.A.; Sathiyaseelan, A.; Veeraraghavan, V.P.; Kim, K.; Wang, M. Chemical composition, antioxidant, and anti-diabetic activities of ethyl acetate fraction of Stachys riederi var. japonica (Miq.) in streptozotocin-induced type 2 diabetic mice. Food Chem. Toxicol. 2021, 155, 112374. [CrossRef]

9. Gao, X.; Tian, Y.; Randell, E.; Zhou, H.; Sun, G. Unfavorable associations between serum trimethylamine N-oxide and L-carnitine levels with components of metabolic syndrome in the newfoundland population. Front. Endocrinol. (Lausanne) 2019, 10, 168. [CrossRef] [PubMed]

10. Mariadoss, A.V.A.M.; Park, S.; Saravanakumar, K.; Sathiyaseelan, A.; Wang, M. Ethyl acetate fraction of Helianthus tuberosus L. induces anti-diabetic, and wound-healing activities in insulin-resistant human liver cancer and mouse fibroblast cells. Antioxidants 2021, 10, 99. [CrossRef]

11. Zheng, Y.; Ley, S.; Hu, F. Global aetiology and epidemiology of type 2 diabetes mellitus and its complications. Nat. Rev. Endocrinol. 2018, 14, 88-98. [CrossRef]

12. Guo, X.; Ye, X.; Sun, Y.; Wu, D.; Wu, N.; Hu, Y.; Chen, S. Ultrasound effects on the degradation kinetics, structure, and antioxidant activity of sea cucumber fucoidan. J. Agric. Food Chem. 2014, 62, 1088-1095. [CrossRef]

13. Zhang, M.; Chen, L.; Liu, Y.; Chen, M.; Zhang, S.; Kong, D. Sea cucumber Cucumaria frondosa fucoidan inhibits osteosarcoma adhesion and migration by regulating cytoskeleton remodeling. Oncol. Rep. 2020, 44, 469-476. [CrossRef]

14. Li, C.; Niu, Q.; Li, S.; Zhang, X.; Liu, C.; Cai, C.; Li, G.; Yu, G. Fucoidan from sea cucumber Holothuria polii: Structural elucidation and stimulation of hematopoietic activity. Int. J. Biol. Macromol. 2020, 154, 1123-1131. [CrossRef]

15. Li, Q.; Jiang, S.; Shi, W.; Qi, X.; Song, W.; Mou, J.; Yang, J. Structure characterization, antioxidant and immunoregulatory properties of a novel fucoidan from the sea cucumber Stichopus chloronotus. Carbohyd. Polym. 2020, 231, 115767. [CrossRef] [PubMed]

16. Xu, X.; Chang, Y.; Xue, C.; Wang, J.; Shen, J. Gastric protective activities of sea cucumber fucoidans with different molecular weight and chain conformations: A structure-activity relationship investigation. J. Agric. Food Chem. 2018, 66, 8615-8622. [CrossRef]

17. Zhu, Y.; Tian, Y.; Wang, N.; Chang, Y.; Xue, C.; Wang, J. Structure-function relationship analysis of fucoidan from sea cucumber [Holothuria tubulosa] on ameliorating metabolic inflammation. J. Food Biochem. 2021, 45, e13500. [CrossRef] [PubMed]

18. Hu, S.; Wang, J.; Wang, J.; Yang, H.; Yan, X.; Su, L. Fucoidan from Acaudina molpadioides improves insulin resistance by altering gut microbiota dysfunction. J. Funct. Food. 2019, 57, 59-67. [CrossRef]

19. Wang, J.; Hu, S.; Jiang, W.; Song, W.; Cai, L.; Wang, J. Fucoidan from sea cucumber may improve hepatic inflammatory response and insulin resistance in mice. Int. Immunopharmacol. 2016, 31, 15-23. [CrossRef]

20. Wang, Y.; Wang, J.; Zhao, Y.; Hu, S.; Shi, D.; Xue, C. Fucoidan from sea cucumber Cucumaria frondosa exhibits anti-hyperglycemic effects in insulin resistant mice via activating the PI3K/PKB pathway and GLUT4. J. Biosci. Bioeng. 2016, 121, 36-42. [CrossRef] [PubMed] 
21. Zhao, F.; Liu, Q.; Cao, J.; Xu, Y.; Pei, Z.; Fan, H.; Yuan, Y.; Shen, X.; Li, C. A sea cucumber [Holothuria leucospilota] polysaccharide improves the gut microbiome to alleviate the symptoms of type 2 diabetes mellitus in Goto-Kakizaki rats. Food Chem. Toxicol. 2020, 135, 110886. [CrossRef] [PubMed]

22. Li, S.; Li, J.; Mao, G.; Yan, L.; Hu, Y.; Ye, X.; Tian, D.; Linhardt, R.; Chen, S. Effect of the sulfation pattern of sea cucumber-derived fucoidan oligosaccharides on modulating metabolic syndromes and gut microbiota dysbiosis caused by HFD in mice. J. Funct. Food. 2019, 55, 193-210. [CrossRef]

23. Yu, L.; Xue, C.; Chang, Y.; Xu, X.; Ge, L.; Liu, G.; Wang, Y. Structure elucidation of fucoidan composed of a novel tetrafucose repeating unit from sea cucumber Thelenota ananas. Food Chem. 2014, 146, 113-119. [CrossRef] [PubMed]

24. Hu, S.; Xia, G.; Wang, J.; Wang, Y.; Li, Z.; Xue, C. Fucoidan from sea cucumber protects against high-fat high-sucrose diet-induced hyperglycaemia and insulin resistance in mice. J. Funct. Food. 2014, 10, 128-138. [CrossRef]

25. Wright, C.M.; Bezabhe, W.; Fitton, J.H.; Stringer, D.N.; Bereznicki, L.R.E.; Peterson, G.M. Effect of a fucoidan extract on insulin resistance and cardiometabolic markers in obese, nondiabetic subjects: A randomized, controlled trial. J. Altern. Complement. Med. 2019, 25, 346-352. [CrossRef]

26. Zhu, Z.; Zhu, B.; Sun, Y.; Ai, C.; Wang, L.; Wen, C.; Yang, J.; Song, S.; Liu, X. Sulfated polysaccharide from sea cucumber and its depolymerized derivative prevent obesity in association with modification of gut microbiota in high-fat diet-fed mice. Mol. Nutr. Food Res. 2018, 62, 1800446. [CrossRef]

27. Yang, C.; Chung, D.; Shin, I.S.; Lee, H.; Kim, J.; Lee, Y.; You, S. Effects of molecular weight and hydrolysis conditions on anticancer activity of Fucoidans from sporophyll of Undaria pinnatifida. Int. J. Biol. Macromol. 2008, 43, 433-437. [CrossRef] [PubMed]

28. Hou, Y.; Wang, J.; Jin, W.; Zhang, H.; Zhang, Q. Degradation of Laminaria japonica fucoidan by hydrogen peroxide and antioxidant activities of the degradation products of different molecular weights. Carbohyd. Polym. 2012, 87, 153-159. [CrossRef] [PubMed]

29. Li, X.; Wu, N.; Chen, Y.; Tan, J.; Wang, J.; Geng, L.; Qin, Y.; Zhang, Q. Degradation of different molecular weight fucoidans and their inhibition of TGF- $\beta 1$ induced epithelial-mesenchymal transition in mouse renal tubular epithelial cells. Int. J. Biol. Macromol. 2020, 151, 545-553. [CrossRef]

30. Li, B.; Zhao, R.; Wei, X. Anticoagulant activity of fucoidan form Hizikia fusiforme. Agro Food Ind. Hi-Tech. 2008, 19, $22-24$.

31. Cho, M.; Lee, B.; You, S. Relationship between oversulfation and conformation of low and high molecular weight fucoidans and evaluation of their in vitro anticancer activity. Molecules 2010, 16, 291-297. [CrossRef]

32. Koyanagi, S.; Tanigawa, N.; Nakagawa, H.; Soeda, S.; Shimeno, H. Oversulfation of fucoidan enhances its anti-angiogenic and antitumor activities. Biochem. Pharmacol. 2003, 65, 173-179. [CrossRef]

33. Li, S.; Li, J.; Zhi, Z.; Hu, Y.; Ge, J.; Ye, X.; Tian, D.; Linhardt, R.J.; Chen, S. 4-O-Sulfation in sea cucumber fucodians contribute to reversing dyslipidiaemia caused by HFD. Int. J. Biol. Macromol. 2017, 99, 96-104. [CrossRef]

34. Li, S.; Li, J.; Mao, G.; Wu, T.; Hu, Y.; Ye, X.; Tian, D.; Linhardt, R.J.; Chen, S. A fucoidan from sea cucumber Pearsonothuria graeffei with well-repeated structure alleviates gut microbiota dysbiosis and metabolic syndromes in HFD-fed mice. Food Funct. 2018, 9 , 5371-5380. [CrossRef]

35. Mandal, R.; Mateu, C.G.; Chattopadhyay, K.; Pujol, C.A.; Damonte, E.B.; Ray, B. Structural features and antiviral activity of sulphated fucans from the brown seaweed Cystoseira indica. Antivir. Chem. Chemother. 2007, 18, 153-162. [CrossRef]

36. Pereira, M.S.; Melo, F.R.; Mourão, P.A.S. Is there a correlation between structure and anticoagulant action of sulfated galactans and sulfated fucans? Glycobiology 2002, 12, 573-580. [CrossRef] [PubMed]

37. Fonseca, R.J.C.; Santos, G.R.C.; Mourão, P.A.S. Effects of polysaccharides enriched in 2,4-disulfated fucose units on coagulation, thrombosis and bleeding Practical and conceptual implications. Thromb. Haemost. 2009, 102, 829-836. [CrossRef]

38. Chevolot, L.; Mulloy, B.; Ratiskol, J.; Foucault, A.; Colliec-Jouault, S. A disaccharide repeat unit is the major structure in fucoidans from two species of brown algae. Carbohydr. Res. 2001, 330, 529-535. [CrossRef]

39. Chang, Y.; Hu, Y.; Yu, L.; McClements, D.; Xu, X.; Liu, G.; Xue, C. Primary structure and chain conformation of fucoidan extracted from sea cucumber Holothuria tubulosa. Carbohydr. Polym. 2016, 136, 1091-1097. [CrossRef] [PubMed]

40. Abdelmageed, M.E.; Shehatou, G.S.G.; Suddek, G.M.; Salem, H.A. Protocatechuic acid improves hepatic insulin resistance and restores vascular oxidative status in type-2 diabetic rats. Environ. Toxicol. Pharmacol. 2021, 83, 103577. [CrossRef]

41. Hu, S.; Du, M.; Su, L.; Yang, H. Phosphatidylserine from Portunus trituberculatus eggs alleviates insulin resistance and alters the gut microbiota in high-fat-diet-fed mice. Mar. Drug. 2020, 18, 483. [CrossRef] [PubMed]

42. Mirzaalian, Y.; Nourian, M.; Gholamalizadeh, M.; Doaei, S.; Hatami, M.; Hassanzadeh, A.; Askari, G.; Farahi, R. The association of quantitative insulin sensitivity indices [HOMA-IR and QUICKI] with anthropometric and cardiometabolic indicators in adolescents. Arch. Med. Sci. Atheroscler. Dis. 2019, 4, e32. [CrossRef] [PubMed] 